\title{
Real-world risk assessment and treatment initiation among patients with myelofibrosis at community oncology practices in the United States
}

\author{
Srdan Verstovsek ${ }^{1}$ • Jingbo $\mathrm{Yu}^{2}$ • Jonathan K. Kish ${ }^{3}$ - Dilan Paranagama ${ }^{2} \cdot$ Jill Kaufman $^{3}$ - Callan Myerscough ${ }^{3,4}$. \\ Michael R. Grunwald ${ }^{5} \cdot$ Philomena Colucci $^{2} \cdot$ Ruben Mesa $^{6}$
}

Received: 13 April 2020 / Accepted: 22 April 2020 / Published online: 7 May 2020

(C) The Author(s) 2020

\begin{abstract}
Myelofibrosis (MF) is a chronic myeloproliferative neoplasm with a prevalence of 4 to 6 per 100,000 people in the USA. Treatment recommendations are risk-adapted. This study was conducted to evaluate how physicians risk-stratify patients at the time of MF diagnosis, the accuracy of the risk stratification, and its effect on treatment selection. Medical charts were reviewed at US community hematology/oncology practices in the Cardinal Health Oncology Provider Extended Network; patient clinical characteristics, risk stratification, and treatment data were collected. Physician-assigned risk categorizations were compared with data-derived risk categorizations based on the International Prognostic Scoring System, the system recommended at diagnosis. A total of 491 patients diagnosed with MF between 2012 and 2016 (mean [SD] age at diagnosis, 65.4 [11.8] years; 54.8\% male, 69.2\% with primary MF) were included. Risk categorization was not assigned for $30.1 \%$ of patients. Of the patients with a physicianassigned risk categorization $(n=343)$, a scoring system was used in $49.9 \%$. Compared with data-derived risk categorizations, $42.9 \%$ of physician-assigned risk categorizations were incorrect; $85.0 \%$ of incorrect physician-assigned risk categorizations were underestimations. Notably, $38.5 \%$ of patients with data-derived intermediate- or high-risk categorizations did not initiate treatment within 120 days of diagnosis. Among patients with data-derived intermediate risk, those with an underestimated physician-assigned risk categorization were significantly less likely to receive treatment within 120 days of diagnosis $(51.6 \%$ with correct physician-assigned categorization vs $18.5 \%$ with underestimated risk categorization; $P=0.0023$ ). These results highlight the gap in risk assessment and the importance of accurate risk stratification at diagnosis.
\end{abstract}

Keywords Myelofibrosis $\cdot$ Risk stratification $\cdot$ IPSS $\cdot$ Chart review $\cdot$ Treatment patterns

Electronic supplementary material The online version of this article (https://doi.org/10.1007/s00277-020-04055-w) contains supplementary material, which is available to authorized users.

Srdan Verstovsek

sverstov@mdanderson.org

1 Department of Leukemia, The University of Texas MD Anderson Cancer Center, 1515 Holcombe Blvd, Houston, TX 77030, USA

2 Incyte Corporation, Wilmington, DE, USA

3 Cardinal Health Specialty Solutions, Dublin, OH, USA

4 Present address: Ohio State University, Columbus, OH, USA

5 Levine Cancer Institute, Atrium Health, Charlotte, NC, USA

6 UT Health San Antonio Cancer Center, San Antonio, TX, USA

\section{Background}

Myelofibrosis (MF) is a myeloproliferative neoplasm characterized by bone marrow fibrosis, extramedullary hematopoiesis, leukoerythroblastosis, and, frequently, the presence of $J A K 2, C A L R$, or $M P L$ driver mutations [1, 2]. Clinical manifestations often include anemia, splenomegaly, and constitutional symptoms (e.g., weight loss, fever, night sweats) $[3,4]$. In the USA, the estimated MF prevalence is between 4 and 6 per 100,000 people [5], and the median survival in patients with primary MF ranges from 2 to 11 years [3]. This wide range in survival time is indicative of the heterogeneity of disease severity and patient prognosis, which may be estimated with a number of scoring systems. The National 
Comprehensive Cancer Network (NCCN) Clinical Practice Guidelines in Oncology (NCCN Guidelines ${ }^{\circledR}$ ) for Myeloproliferative Neoplasms, which became available in 2017, recommend the use of the International Prognostic Scoring System (IPSS) for risk stratification at diagnosis (Table 1). IPSS risk stratification assigns 1 point for each of the following prognostic variables: age $>65$ years, white blood cell (WBC) count $>25 \times 10^{9} / \mathrm{L}$, hemoglobin $<10 \mathrm{~g} / \mathrm{dL}$, peripheral blood blasts $\geq 1 \%$, and presence of constitutional symptoms. However, stratification models are evolving. In addition to the IPSS, the Dynamic IPSS (DIPSS) and the DIPSS-Plus, also referenced in the NCCN Guidelines MF algorithms, are recommended for use during treatment rather than at diagnosis [6, 7]. Mutation-enhanced IPSS (MIPSS70) can be used for risk stratification of patients with primary MF aged $\leq 70$ years [8], and the Myelofibrosis Secondary to Polycythemia Vera and Essential ThrombocythemiaPrognostic Model (MYSEC-PM) has been developed for risk stratification of patients with secondary MF [9].

Treatment recommendations in the NCCN Guidelines are risk-adapted, reinforcing the importance of accurately assessing patient risk categorization at diagnosis [2]. Despite the central role that accurate risk categorization plays at the time of diagnosis with respect to treatment selection and prognostication, limited data are available on how initial risk is assessed in real-world clinical practice [10]. This retrospective medical chart review evaluated how patients with MF were risk-stratified at diagnosis, the impact that the use of a prognostic risk scoring system had on the accuracy of risk stratification, and the effect of the accuracy of risk stratification on the timing of treatment initiation at community hematology/ oncology practices in the USA.

Table 1 Risk categorization per International Prognostic Scoring System (IPSS) for patients with myelofibrosis (MF) [3]

\begin{tabular}{lll}
\hline & Points & \\
& 0 & 1 \\
Prognostic variable & & \\
Age, years & $\leq 65$ & $>65$ \\
WBC count, $\times 10^{9} / \mathrm{L}$ & $\leq 25$ & $>25$ \\
Hemoglobin, g/dL & $\geq 10$ & $<10$ \\
Peripheral blood blast, \% & $<1$ & $\geq 1$ \\
Constitutional symptoms & No & Yes \\
& Points & \\
Risk group & & \\
Low & 0 & \\
Intermediate 1 & 1 & \\
Intermediate 2 & 2 & \\
High & $\geq 3$ & \\
\hline
\end{tabular}

$W B C$ white blood cell

\section{Methods}

\section{Study design and patients}

This retrospective medical chart review was conducted at US community hematology/oncology practices in the Cardinal Health Oncology Provider Extended Network (OPEN), which includes practices across the country. Adult patients diagnosed with primary MF, post-polycythemia vera (PV) MF, or postessential thrombocythemia (ET) MF between January 2012 and December 2016 and who received care for $\geq 6$ months (or died within 6 months of diagnosis) at the participating practices were included. Between May and July of 2018, physicians extracted data documented at the time of MF diagnosis and during follow-up visits from medical charts for patients under their care and entered the data into an electronic case report form (eCRF). The eCRF included questions pertaining to clinical characteristics, risk stratification method used and the risk level assigned (if applicable) by treating physicians at the time of diagnosis, and treatments administered for MF. Clinical characteristics included patient demographics, MF type, mutation testing, spleen status, transfusion dependence, MF-related symptoms, hemoglobin level, WBC count, platelet count, peripheral blood blast percentage, and medical history. Risk stratification method choices included IPSS, DIPSS, DIPSS-Plus, and clinical/qualitative judgment (i.e., the provider indicated that a formal prognostic scoring system was not used). When a specific risk stratification method was used, data were collected regarding the risk category assigned and the risk assessment score, if documented. For patients whose risk was assigned based on clinical/ qualitative judgment, the risk category choices were low, intermediate, or high risk; the eCRF did not distinguish between intermediate 1 and intermediate 2. Physician-assessed risk categorization used for this analysis was the score or risk categorization documented in the medical record within 30 days of the diagnosis of MF.

A data-derived IPSS risk categorization was determined for all patients with individual risk variables that included age, WBC count, hemoglobin level, peripheral blast count, and constitutional symptoms (e.g., weight loss, fever, night sweats) at the time of diagnosis. To assess the accuracy of the physician-assigned risk categorization at diagnosis, this data-derived IPSS risk categorization was compared with the physician-assigned risk categorization. In addition, a dataderived risk categorization was determined with risk factor data collected in eCRFs with the same scoring tool (i.e., IPSS, DIPSS, or DIPSS-Plus) used by the treating physician at the time of diagnosis. For providers who indicated that they used their "clinical/qualitative judgment" as opposed to a specific prognostic scoring system when assigning a risk category, the data-derived risk categorizations were limited to low, intermediate, or high risk as calculated with the IPSS. 
In the analysis, patients were defined as having initiated treatment upon diagnosis if any MF-directed treatment (hydroxyurea (HU), interferon (IFN) alfa-2b, pegylated-IFN alfa$2 \mathrm{~b}$, ruxolitinib, a clinical trial with an investigational drug, or referral for hematopoietic cell transplantation (HCT)) was initiated within 120 days of the date of MF diagnosis. Fedratinib was approved for the treatment of MF after the inclusion period of this study and, consequently, was not included as MFdirected therapy but was captured as an investigational drug in a clinical trial [11]. To describe the association of accurate risk categorization and treatment initiation at diagnosis (as defined above), the proportion of patients with a correctly assigned risk categorization who initiated treatment within 120 days was compared with the proportion of patients whose risk was incorrectly assigned versus patients whose risk was underestimated based on the data-derived IPSS score.

\section{Statistics}

Categorical measures were reported as frequency and percentage; continuous measures were described with mean and median. The discordance between physician-assigned risk categorization (low, intermediate, or high) and data-derived risk categorization was assessed with the Cohen's kappa coefficient and $95 \% \mathrm{CI}$, and $P$ value for the test of symmetry was used to assess the level of agreement between the two methods. The differences in the proportion of patients treated versus not treated at diagnosis by correct versus underestimated risk category was assessed by chi-square tests.

\section{Results}

\section{Patients}

Records from 491 patients with MF from 45 community hematology/oncology providers in OPEN were included (Table 2). Patients were predominantly white $(65.2 \%)$ and male $(54.8 \%$ ), with a mean (SD) age at diagnosis of 65.4 (11.8) years. More patients had primary MF (69.2\%) than post-PV (17.7\%) or post-ET (13.0\%) MF. Median (interquartile range) disease duration at the time of the study was 27.3 (19.1-40.2) months.

\section{Physician-reported risk stratification at diagnosis}

A risk category (low, intermediate, or high) was assigned by the physician at the time of MF diagnosis for 343 patients (69.9\%; Table 3); a considerable proportion of patients (148/ $491[30.1 \%]$ ) did not have a risk category documented at the time of diagnosis. Of those patients assigned a risk category, approximately half received a risk assignment with a scoring system (171/343 [49.9\%]). The most commonly used scoring system was DIPSS (83/171 [48.5\%]), followed by IPSS (54/ $171[31.6 \%])$ and DIPSS-Plus (34/171 [19.9\%]). The remainder of patients' risk categorizations (172/343 [50.1\%]) were assigned using clinical/qualitative judgment. Of the patients assigned a risk category by the physician at diagnosis, $42 / 343$ (12.2\%) were classified as low risk, 200/343 (58.3\%) intermediate risk, and 101/343 (29.5\%) high risk.

\section{Data-derived IPSS risk categorization}

Among all 491 patients, the data-derived IPSS risk category was low for 32 patients (6.5\%), intermediate for 207 (42.2\%), and high for $250(50.9 \%)$. For the 343 patients who received a physician-assigned risk category at diagnosis, $20(5.8 \%)$ patients were categorized as low risk, $135(39.3 \%)$ as intermediate risk, and $188(54.8 \%)$ as high risk according to dataderived IPSS risk categorization (Table 4). Of the 148 patients who did not receive physician-assigned risk categorization at diagnosis, the data-derived IPSS risk category was low in 12 (8.1\%) patients, intermediate in $72(49.3 \%)$, and high in 62 (42.5\%); risk category was incalculable in $2(1.4 \%)$ patients owing to the absence of peripheral blast percentage at the time of diagnosis.

\section{Comparison of physician-assigned versus data-derived risk categorization}

Based on data-derived IPSS categorization, 147/343 patients $(42.9 \%)$ were inaccurately risk-stratified by their physician; most of these inaccurate assessments (125/147 [85.0\%]) were underestimations of risk (Table 4).

In a separate analysis, in which a data-derived risk category was determined with the same system used by the physician (i.e., IPSS, DIPSS, DIPSS-Plus, or IPSS when the physician used clinical/qualitative judgment), 141/343 patients (41.1\%) were inaccurately risk-stratified by their physician. According to the data-derived risk categorization, the physician-assigned risk category was an underestimation in 110/141 patients (78.0\%). The majority (70.9\% [78/110]) of patients whose risk was underestimated were high-risk patients incorrectly categorized as intermediate risk by their providers. The use of a scoring system resulted in accurate risk categorization in $68.9 \%$ of patients, whereas $53.5 \%$ of patients were correctly risk-stratified when the physician relied on clinical/qualitative judgment $(P<0.01)$.

\section{Treatment initiation at diagnosis}

Of the 42 patients with physician-assigned low risk, $9(21.4 \%)$ were referred for HCT, 12 (28.6\%) were treated with HU or IFN/pegylated-IFN, and the other $30(71.4 \%)$ did not receive any pharmacologic treatments within 120 days of diagnosis (Fig. 1). Of the 200 patients assigned intermediate risk, 56 
Table 2 Patient demographics and clinical characteristics at diagnosis as reported by physicians

\begin{tabular}{|c|c|}
\hline & Patients, $N=491$ \\
\hline Mean (SD) age at diagnosis, years & $65.4(11.8)$ \\
\hline \multicolumn{2}{|l|}{ Sex, $n(\%)$} \\
\hline Male & $269(54.8)$ \\
\hline \multicolumn{2}{|l|}{ Race, $n(\%)$} \\
\hline White & $320(65.2)$ \\
\hline Black/African American & $104(21.2)$ \\
\hline Asian & $50(10.2)$ \\
\hline American Indian or Alaska Native & $6(1.2)$ \\
\hline Native Hawaiian/Pacific Islander & $5(1.0)$ \\
\hline Other & $6(1.2)$ \\
\hline \multicolumn{2}{|l|}{ Geographic region of treating physician practice, $n(\%)$} \\
\hline South & $16(35.6)$ \\
\hline West & $12(26.7)$ \\
\hline Northeast & $9(20.0)$ \\
\hline Midwest & $8(17.8)$ \\
\hline \multicolumn{2}{|l|}{ Type of MF, $n(\%)$} \\
\hline Primary MF & $340(69.2)$ \\
\hline Post-PV MF & $87(17.7)$ \\
\hline Post-ET MF & $64(13.0)$ \\
\hline Median (IQR) disease duration at the time of the study, months & $27.3(19.1-40.2)$ \\
\hline \multicolumn{2}{|l|}{ Palpable spleen, $n(\%)$} \\
\hline Yes & $374(76.2)$ \\
\hline No & $116(23.6)$ \\
\hline Unknown & $1(0.2)$ \\
\hline \multicolumn{2}{|l|}{ Spleen length, $n(\%)$} \\
\hline$<5 \mathrm{~cm}$, spleen not palpable or barely palpable & $76(15.5)$ \\
\hline$\geq 5 \mathrm{~cm}$ but $<10 \mathrm{~cm}$; spleen palpable below the coastal margin & $152(31.0)$ \\
\hline$\geq 10$ to $<20 \mathrm{~cm}$; spleen palpable between the coastal margin and the umbilicus & $113(23.0)$ \\
\hline$\geq 20 \mathrm{~cm}$; spleen palpable near to the umbilicus or severe splenomegaly & $32(6.5)$ \\
\hline Unknown & $1(0.2)$ \\
\hline \multicolumn{2}{|l|}{ Transfusion dependent, $n(\%)$} \\
\hline Yes & $124(25.3)$ \\
\hline No & $366(74.5)$ \\
\hline Unknown & $1(0.2)$ \\
\hline Symptomatic disease at diagnosis, $n(\%)$ & $312(63.5)$ \\
\hline \multicolumn{2}{|l|}{ Lab values, $n(\%)$} \\
\hline Blood blast $>1 \%$ & $299(61.2)$ \\
\hline Hemoglobin $<10 \mathrm{~g} / \mathrm{dL}$ & $291(59.3)$ \\
\hline WBC count $>25 \times 10^{9} / \mathrm{L}$ & $84(17.1)$ \\
\hline Platelets $<100 \times 10^{9} / \mathrm{L}$ & $161(32.8)$ \\
\hline
\end{tabular}

$E T$ essential thrombocythemia, $I Q R$ interquartile range, $M F$ myelofibrosis, $P V$ polycythemia vera, $W B C$ white blood cell
$(28.0 \%)$ were referred for $\mathrm{HCT}, 61(30.5 \%)$ received $\mathrm{HU}$ or IFN/pegylated-IFN, $58(29.0 \%)$ received ruxolitinib, and 81 $(40.5 \%)$ received no pharmacologic treatment within 120 days of diagnosis. Of the 101 patients assigned high risk, 43 $(42.6 \%)$ were referred for HCT, 20 (19.8\%) received HU or IFN/pegylated-IFN, 45 (44.6\%) received ruxolitinib, 1 (1.0\%) received investigational treatments in a clinical trial, and 35 (34.7\%) received no pharmacologic treatment within 120 days of diagnosis. Among the 148 patients who were not assigned a risk category by their physician, $33(22.3 \%)$ were referred for HCT, $32(21.6 \%)$ received HU or IFN/pegylated-IFN, 38 $(25.7 \%)$ received ruxolitinib, and $74(50.0 \%)$ received no 
Table 3 Methods used and risk categories assigned by physicians at the time of myelofibrosis (MF) diagnosis

\begin{tabular}{lc}
\hline & Patients, $n=343$ \\
\hline Method used for physician-assigned risk level & \\
IPSS & $54(15.7)$ \\
DIPSS & $83(24.2)$ \\
DIPSS-Plus & $34(9.9)$ \\
Clinical/qualitative judgment & $172(50.1)$ \\
Physician-assigned risk level & \\
Low & $42(12.2)$ \\
Intermediate & $200(58.3)$ \\
High & $101(29.5)$ \\
\hline
\end{tabular}

DIPSS Dynamic International Prognostic Scoring System, IPSS International Prognostic Scoring System

pharmacologic treatment within 120 days of diagnosis. A total of $43 / 141$ patients $(30.5 \%)$ referred to HCT did not receive pharmacologic treatment within 120 days (Table 5). Overall, 61 patients received HCT within 120 days of diagnosis, including 1 patient assigned low risk, 10 patients assigned intermediate risk, 30 patients assigned high risk, and 20 patients who did not have a physician-assigned risk; the remaining 80 patients referred for HCT had not undergone transplant within the study timeframe.

Among patients with data-derived intermediate risk, those whose physician-assigned risk score was incorrect (including overestimations and underestimations) or underestimated only (excluding overestimations) were significantly less likely to receive any treatment (pharmacologic or HCT referral) within 120 days of diagnosis compared with patients who were correctly risk-stratified by their provider $(51.6 \%$ correct vs $28.2 \%$ incorrect $[P=0.0134]$ and $18.5 \%$ underestimated $[P=0.0023]$; Table 6 and Supplemental Table 1). The results were similar when excluding patients who received HCT (50.6\% correct vs $25.7 \%$ incorrect $[P=0.0120]$ and $15.4 \%$ underestimated $[P=0.0014])$. For patients with data-derived high risk, the rate at which treatment was received within 120 days was not significantly affected by the accuracy of the physician-assessed risk categorization $(63.8 \%$ correct vs $59.1 \%$ incorrect $[P=0.5099]$ and $57.8 \%$ underestimated $[P=$ $0.4142])$. The results were again similar when excluding patients who received HCT $(57.1 \%$ with correct risk score vs $59.8 \%$ incorrect $[P=0.7397]$ and $58.8 \%$ underestimated $[P=$ 0.8423]).

\section{Discussion}

Treatment recommendations for MF are guided by patient risk categorization [2]; however, this analysis of US patient records from community practices revealed that nearly one third of patients with MF did not receive a risk categorization at diagnosis. Furthermore, among patients who did receive a physician-assigned risk categorization at diagnosis, nearly one third were based on scoring systems not recommended for use at the time of diagnosis [2], and half were based on clinical judgment without use of a formal risk stratification system. When compared with data-derived IPSS risk categorization, physician-assigned risk categorization was least accurate when based on clinical/qualitative judgment (only $53.5 \%$ of patients were correctly risk-stratified when the physician relied on clinical/qualitative judgment compared with
Table 4 Risk categorization at the time of myelofibrosis (MF) diagnosis, physician-assigned versus data-derived

\begin{tabular}{|c|c|c|c|c|}
\hline & \multirow[t]{2}{*}{ Total } & \multicolumn{3}{|c|}{ Data-derived risk categorizations (IPSS only)* } \\
\hline & & Low & Intermediate & High \\
\hline Physician-assigned risk category, $n$ (row \%) & 343 & $20(5.8)$ & $135(39.3)$ & $188(54.8)$ \\
\hline Low & 42 & $10(23.8)$ & $26(61.9)$ & $6(14.3)$ \\
\hline Intermediate & 200 & $10(5.0)$ & $97(48.5)$ & $93(46.5)$ \\
\hline High & 101 & 0 & $12(11.9)$ & $89(88.1)$ \\
\hline $\begin{array}{l}\text { Incorrect risk categorization by } \\
\text { physician, } n \text { (column \%) }\end{array}$ & 147 (42.9) & $10(50.0)$ & $38(28.1)$ & $99(52.7)$ \\
\hline Underestimated, $n(\%)^{\dagger}$ & $125(85.0)$ & - & $26(68.4)$ & $99(100.0)$ \\
\hline Overestimated, $n(\%)^{\dagger}$ & $22(15.0)$ & $10(100.0)$ & $12(31.6)$ & - \\
\hline Risk not assigned by physician, $n$ (row $\%$ ) & $148^{*}$ & $12(8.1)$ & $72(49.3)$ & $62(42.5)$ \\
\hline
\end{tabular}

IPSS International Prognostic Scoring System

*Cohen's kappa $(95 \%$ CI $)=0.2881(0.2097-0.3664) ; P<0.001$

$\dagger$ Of incorrect total in each column. Values in bold indicate physician-correctly estimated risk. Values in italics indicate physician-underestimated risk. Values in bold-italics indicate physician-overestimated risk

${ }^{\star}$ In 2 patients, an IPSS risk categorization could not be determined because of missing data pertaining to peripheral blast percentage 


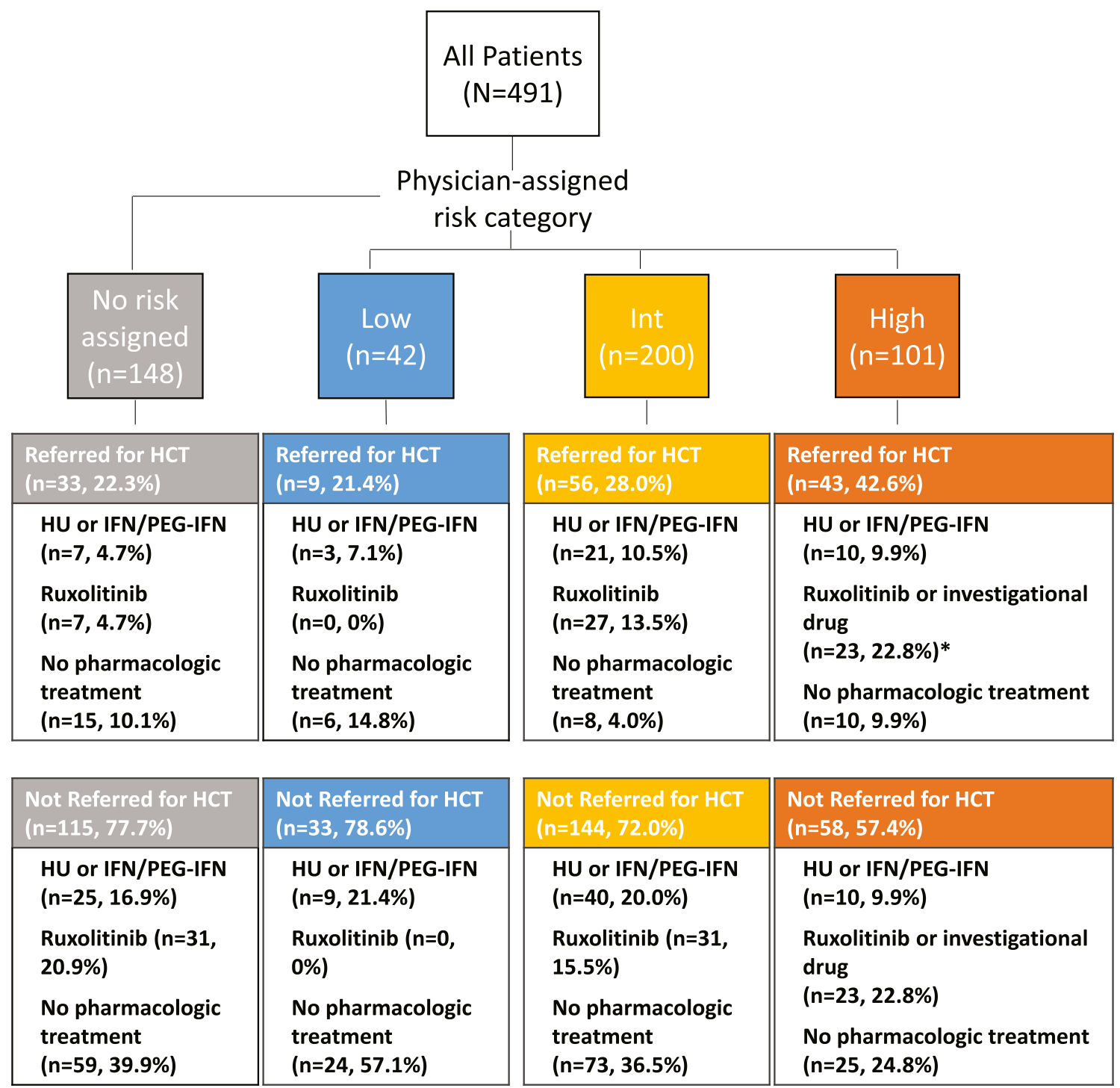

Fig. 1 Patient flow chart. The chart shows the selection of patients into groups defined by physician-assigned risk category and patterns of treatment within 120 days of the date of MF diagnosis. Treatment categories are not mutually exclusive. $H C T$ hematopoietic cell transplantation, $H U$

hydroxyurea, IFN interferon, Int intermediate risk, $M F$ myelofibrosis, $P E G$ pegylated. Asterisk indicates that 1 patient assigned high risk received investigational treatment in a clinical trial

$68.9 \%$ when using a scoring system). Even among patients who received a physician-assigned risk categorization based on a scoring system, nearly one third were misclassified when compared with data-derived risk categorizations. The vast majority $(85 \%)$ of misclassifications were underestimations.

Assignment of a risk classification is important for the management of MF because treatments are risk-stratified [2]. Although NCCN Guidelines for MPN were not available when the patients in this study were diagnosed, the current NCCN Guidelines and published literature support the use of IPSS at the time of MF diagnosis for risk stratification and survival estimation $[2,3,6]$. The DIPSS and DIPSSPlus systems were intended for risk stratification and estimation of survival during the course of the disease and following treatment $[2,3,6]$. Observation is recommended for asymptomatic patients (low and intermediate 1 risks). In patients with symptomatic low-risk disease, recommended pharmacologic treatments include HU for hyperproliferative manifestations (from thrombocytosis or leukocytosis), and IFN or ruxolitinib. Ruxolitinib is also recommended for symptomatic patients with intermediate 1-risk disease and patients with intermediate 2 or high risk with platelet counts $\geq 50,000 / \mu \mathrm{L}$ who are not eligible for HCT. Fedratinib was recently approved for the treatment of adult patients with intermediate 2-risk or high-risk primary or secondary (post-PV or postET) MF [11]. Limiting fedratinib to patients with platelet counts $\geq 50,000 / \mu \mathrm{L}$ is recommended, including patients previously treated with ruxolitinib with no or loss of response [2]; however, approval came after the inclusion period for this study. Investigational drugs are a recommended treatment 
Table 5 Treatment initiation at diagnosis (initiated within 120 days of the date of myelofibrosis (MF) diagnosis) by provider-assigned risk category

\begin{tabular}{|c|c|c|c|c|c|c|}
\hline & \multirow[b]{2}{*}{$\begin{array}{l}\text { All patients } \\
(n=491)\end{array}$} & \multicolumn{5}{|c|}{ Provider-assigned risk category } \\
\hline & & $\begin{array}{l}\text { No risk score } \\
\text { recorded }(n=148)\end{array}$ & $\begin{array}{l}\text { Low } \\
(n=42)\end{array}$ & $\begin{array}{l}\text { Intermediate } \\
(n=200)\end{array}$ & $\begin{array}{l}\text { High } \\
(n=101)\end{array}$ & $\begin{array}{l}\text { Intermediate/ } \\
\text { high } \\
(n=301)\end{array}$ \\
\hline Referred for HCT, $n(\%)$ & $141(28.7)$ & $33(22.3)$ & $9(21.4)$ & $56(28.0)$ & $43(42.6)$ & $99(32.9)$ \\
\hline Any pharmacologic treatment & $98(69.5)$ & $14(42.4)$ & $3(33.3)$ & $48(85.7)$ & $33(76.7)$ & $81(81.8)$ \\
\hline HU or IFN/PEG-IFN as first treatment & $41(41.8)$ & $7(50.0)$ & $3(100.0)$ & $21(43.8)$ & $10(30.3)$ & $31(38.3)$ \\
\hline $\begin{array}{l}\text { Ruxolitinib or investigational } \\
\text { treatments as first treatment }\end{array}$ & $57(58.2)$ & $7(50.0)$ & 0 & $27(56.3)$ & $23(69.7)$ & $50(61.7)$ \\
\hline Received HCT & $61(12.4)$ & $20(13.5)$ & $1(2.4)$ & $10(5.0)$ & $30(29.7)$ & $40(13.3)$ \\
\hline Not treated & $43(30.5)$ & $15(45.5)$ & $6(66.7)$ & $8(14.3)$ & $10(23.3)$ & $18(18.2)$ \\
\hline Not referred for HCT, $n(\%)$ & $350(71.3)$ & $115(77.7)$ & $33(78.6)$ & $144(72.0)$ & $58(57.4)$ & $202(67.1)$ \\
\hline Any pharmacologic treatment & $169(48.3)$ & $56(48.7)$ & $9(27.3)$ & $71(49.3)$ & $33(56.9)$ & $104(51.5)$ \\
\hline HU or IFN/PEG-IFN as first treatment & $84(49.7)$ & $25(44.6)$ & $9(100.0)$ & $40(56.3)$ & $10(30.3)$ & $50(48.1)$ \\
\hline $\begin{array}{l}\text { Ruxolitinib or investigational } \\
\text { treatments as first treatment }\end{array}$ & $85(50.3)$ & $31(55.4)$ & 0 & $31(43.7)$ & $23(69.7)$ & $54(51.9)$ \\
\hline Not treated & $181(51.7)$ & $59(51.3)$ & $24(72.7)$ & $73(50.7)$ & $25(43.1)$ & $98(48.5)$ \\
\hline
\end{tabular}

$H C T$ hematopoietic cell transplantation, $H U$ hydroxyurea, $I F N$ interferon, $P E G$ pegylated

option in all MF risk categories (low risk, intermediate 1 risk, and intermediate 2 and high risks with platelet counts $\geq 50,000 / \mu \mathrm{L})$. Referral for evaluation of HCT is a recommended treatment option for all patients except those with low-risk disease. Misclassification of patients may result in misaligned treatment strategies. Patients with intermediate risk whose physician-assessed risk was underestimated were significantly less likely to receive treatment within 120 days following diagnosis than patients who received the correct risk score. Although some high-risk patients were undercategorized by their provider as intermediate risk, they were likely to still receive recommended treatments because treatment recommendations for high- and intermediate-risk MF are similar [2]. Of the patients classified as low risk, $71.4 \%$ received no pharmacologic treatment. Although no treatment may be appropriate for asymptomatic patients with low-risk MF, 76.2\% $(32 / 42)$ of the patients who were classified as low risk by a physician were determined (based on data) to have either intermediate or high risk. Furthermore, while HU and IFN are not recommended for patients with intermediate 2 risk, patients in this risk category received $\mathrm{HU}$ or IFN at similar rates as ruxolitinib or investigational drugs, despite a demonstrated survival advantage with ruxolitinib in the phase 3 COMFORT-1/2 clinical trials $[12,13]$. Of patients assessed as low risk by a treating physician, $21.4 \%$ were referred for HCT, a treatment option that is not recommended for patients with low risk. It should be noted that there might be situations in which deviating from NCCN Guidelines-recommended therapy is appropriate. For example, many MF treatments can lower blood counts, and low counts (especially anemia) are a major issue in MF $[6,14]$. Therefore, physicians may choose not to start therapy recommended by NCCN owing to low or borderline blood counts [14]. Likewise, various considerations for HCT, such as patient age, race, insurance coverage, and donor matching, can result in low levels of referral when compared with guideline recommendations $[15,16]$.

The limitations of this study are consistent with a retrospective medical chart review, such as potential for patient selection bias at sites and record completeness. The sample size for patients whose risk was overestimated was too small to allow for a rigorous statistical analysis. Most patients in the study were diagnosed with primary MF, for which the use of IPSS, DIPSS, and DIPSS-Plus has been validated [2]. These risk assessment tools have not been validated in post-ET and post-PV MF [2], and other tools have been proposed for use with these patients [9].

\section{Conclusions}

Analysis of chart records revealed potential improvements for the management of MF, especially concerning risk stratification at diagnosis. Risk stratification is recommended for patients with MF to guide treatment choice, yet no risk categorization was assigned at diagnosis for approximately $30 \%$ of patients included in this study. When medical records were used to assign data-derived risk classifications and compared with the physician-assigned risk categorizations at the time of MF diagnosis, approximately $40 \%$ of the physician-assigned categorizations were found to be inaccurate. However, assignment of an accurate risk categorization did not guarantee that patients received recommended treatment because most patients with intermediate- or high-risk disease did not initiate 


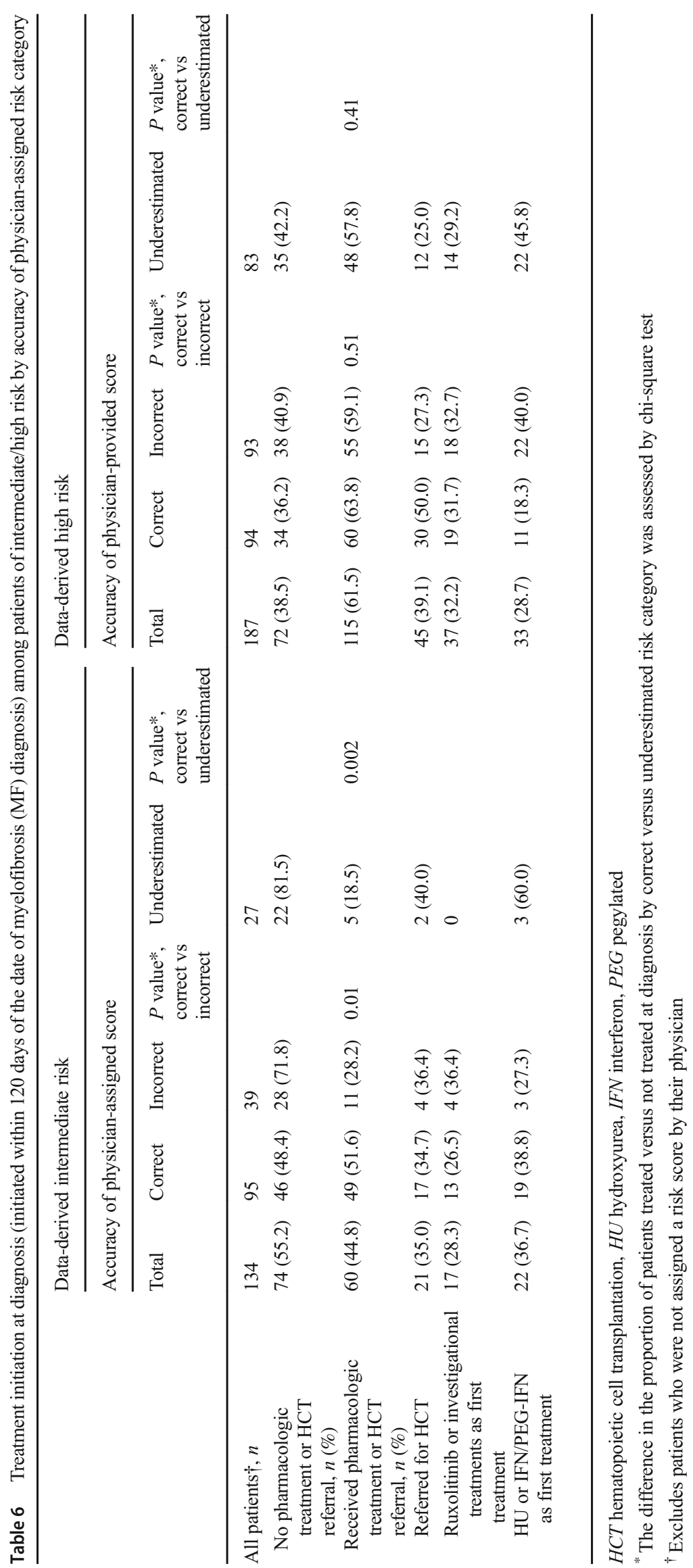


treatment within 120 days of diagnosis. Of those patients who received pharmacologic treatment, half were treated with $\mathrm{HU}$ or IFN, which are not recommended for the treatment of intermediate- and high-risk patients. Among patients with intermediate-risk disease, those whose risk was underestimated by their provider were less likely to initiate recommended pharmacologic treatment compared with those who received a correct risk categorization. Treatment recommendations are risk-stratified, and therefore appropriate treatment strategy is dependent upon accurate risk categorization. Physician education on NCCN Guidelines and recommendations may improve overall patient management and outcomes.

Acknowledgments Writing assistance was provided by Tania Iqbal, $\mathrm{PhD}$ (Complete Healthcare Communications, LLC, North Wales, PA, a CHC Group company).

Funding information This study was funded by Incyte Corporation (Wilmington, DE).

\section{Compliance with ethical standards}

Ethical approval This study was conducted in accordance with the ethical standards of the Declaration of Helsinki. Because of the retrospective nature of this analysis and the use of de-identified patient data, informed consent was not obtained from patients for this study.

Conflict of interest JY, DP, and PC are employees and shareholders of Incyte Corporation. JKK and JK are employees of Cardinal Health. CM was an employee of Cardinal Health at the time of the study. MRG served as a consultant or in advisory roles for Incyte Corporation, Daiichi Sankyo, Trovagene, Ariad, Amgen, Pfizer, Cardinal Health, BMS/Celgene, Merck, Astellas, Premier, and Agios; received research funding from Incyte Corporation, Amgen, Forma Therapeutics, Janssen, Genentech, and Novartis; and has equity ownership in Medtronic. RM served in a consultancy role for Novartis and received research funding from Incyte Corporation, Genentech, CTI Biopharma, Gilead, NS Pharma, Pfizer, and Promedior. SV has received research funding from Incyte Corporation, Roche, NS Pharma, Celegene, Gilead, Promedior, CTI BioPharma, Genentech, Blueprint Medicines, Novartis, Sierra Oncology, Pharma Essentia, AstraZeneca, Ital Pharma, and Protagonist Therapeutics, and consulting fees from Constellation, Pragmatist, Sierra Oncology, Incyte Corporation, Novartis, and Celgene.

Open Access This article is licensed under a Creative Commons Attribution 4.0 International License, which permits use, sharing, adaptation, distribution and reproduction in any medium or format, as long as you give appropriate credit to the original author(s) and the source, provide a link to the Creative Commons licence, and indicate if changes were made. The images or other third party material in this article are included in the article's Creative Commons licence, unless indicated otherwise in a credit line to the material. If material is not included in the article's Creative Commons licence and your intended use is not permitted by statutory regulation or exceeds the permitted use, you will need to obtain permission directly from the copyright holder. To view a copy of this licence, visit http://creativecommons.org/licenses/by/4.0/.

\section{References}

1. Arber DA, Orazi A, Hasserjian R, Thiele J, Borowitz MJ, Le Beau MM, Bloomfield CD, Cazzola M, Vardiman JW (2016) The 2016 revision to the World Health Organization classification of myeloid neoplasms and acute leukemia. Blood 127(20):2391-2405. https:// doi.org/10.1182/blood-2016-03-643544

2. Referenced with permission from the NCCN Clinical Practice Guidelines in Oncology (NCCN Guidelines $\left.{ }^{\circledR}\right)$ for Myeloproliferative Neoplasms V.3.2019. (C) National Comprehensive Cancer Network, Inc. 2019. All rights reserved. Accessed September 4, 2019. To view the most recent and complete version of the guideline, go online to NCCN.org. NCCN makes no warranties of any kind whatsoever regarding their content, use or application and disclaims any responsibility for their application or use in any way

3. Cervantes F, Dupriez B, Pereira A, Passamonti F, Reilly JT, Morra E, Vannucchi AM, Mesa RA, Demory JL, Barosi G, Rumi E, Tefferi A (2009) New prognostic scoring system for primary myelofibrosis based on a study of the International Working Group for Myelofibrosis Research and Treatment. Blood 113(13):2895-2901. https://doi.org/10.1182/blood-2008-07-170449

4. Mesa RA, Schwager S, Radia D, Cheville A, Hussein K, Niblack J, Pardanani AD, Steensma DP, Litzow MR, Rivera CE, Camoriano J, Verstovsek S, Sloan J, Harrison C, Kantarjian H, Tefferi A (2009) The Myelofibrosis Symptom Assessment Form (MFSAF): an evidence-based brief inventory to measure quality of life and symptomatic response to treatment in myelofibrosis. Leuk Res 33(9): 1199-1203. https://doi.org/10.1016/j.leukres.2009.01.035

5. Mehta J, Wang H, Iqbal SU, Mesa R (2014) Epidemiology of myeloproliferative neoplasms in the United States. Leuk Lymphoma 55(3):595-600. https://doi.org/10.3109/10428194.2013.813500

6. Passamonti F, Cervantes F, Vannucchi AM, Morra E, Rumi E, Pereira A, Guglielmelli P, Pungolino E, Caramella M, Maffioli M, Pascutto C, Lazzarino M, Cazzola M, Tefferi A (2010) A dynamic prognostic model to predict survival in primary myelofibrosis: a study by the IWG-MRT (International Working Group for Myeloproliferative Neoplasms Research and Treatment). Blood 115(9):1703-1708. https://doi.org/10.1182/blood-2009-09-245837

7. Gangat N, Caramazza D, Vaidya R, George G, Begna K, Schwager S, Van Dyke D, Hanson C, Wu W, Pardanani A, Cervantes F, Passamonti F, Tefferi A (2011) DIPSS plus: a refined Dynamic International Prognostic Scoring System for primary myelofibrosis that incorporates prognostic information from karyotype, platelet count, and transfusion status. J Clin Oncol 29(4):392-397. https:// doi.org/10.1200/JCO.2010.32.2446

8. Guglielmelli P, Lasho TL, Rotunno G, Mudireddy M, Mannarelli C, Nicolosi M, Pacilli A, Pardanani A, Rumi E, Rosti V, Hanson CA, Mannelli F, Ketterling RP, Gangat N, Rambaldi A, Passamonti F, Barosi G, Barbui T, Cazzola M, Vannucchi AM, Tefferi A (2018) MIPSS70: mutation-enhanced international prognostic score system for transplantation-age patients with primary myelofibrosis. J Clin Oncol 36(4):310-318. https://doi.org/10.1200/JCO.2017.76.4886

9. Passamonti F, Giorgino T, Mora B, Guglielmelli P, Rumi E, Maffioli M, Rambaldi A, Caramella M, Komrokji R, Gotlib J, Kiladjian JJ, Cervantes F, Devos T, Palandri F, De Stefano V, Ruggeri M, Silver RT, Benevolo G, Albano F, Caramazza D, Merli M, Pietra D, Casalone R, Rotunno G, Barbui T, Cazzola M, Vannucchi AM (2017) A clinical-molecular prognostic model to predict survival in patients with post polycythemia vera and post essential thrombocythemia myelofibrosis. Leukemia 31(12):27262731. https://doi.org/10.1038/leu.2017.169

10. Mesa RA, Miller CB, Thyne M, Mangan J, Goldberger S, Fazal S, Ma X, Wilson W, Paranagama DC, Dubinski DG, Naim A, 
Parasuraman S, Boyle J, Mascarenhas JO (2017) Differences in treatment goals and perception of symptom burden between patients with myeloproliferative neoplasms (MPNs) and hematologists/oncologists in the United States: findings from the MPN Landmark survey. Cancer 123(3):449-458. https://doi.org/ 10.1002/cncr.30325

11. Inrebic ${ }^{\circledR}$ (fedratinib) (2019) Full prescribing information, Celgene Corporation, Summit, NJ

12. Harrison CN, Vannucchi AM, Kiladjian JJ, Al-Ali HK, Gisslinger H, Knoops L, Cervantes F, Jones MM, Sun K, McQuitty M, Stalbovskaya V, Gopalakrishna P, Barbui T (2016) Long-term findings from COMFORT-II, a phase 3 study of ruxolitinib vs best available therapy for myelofibrosis. Leukemia 30(8):1701-1707. https://doi.org/10.1038/leu.2016.148

13. Verstovsek S, Mesa RA, Gotlib J, Levy RS, Gupta V, DiPersio JF, Catalano JV, Deininger M, Miller C, Silver RT, Talpaz M, Winton EF, Harvey JH Jr, Arcasoy MO, Hexner E, Lyons RM, Paquette R, Raza A, Vaddi K, Erickson-Viitanen S, Koumenis IL, Sun W,
Sandor V, Kantarjian HM (2012) A double-blind, placebocontrolled trial of ruxolitinib for myelofibrosis. N Engl J Med 366(9):799-807. https://doi.org/10.1056/NEJMoa1110557

14. Cervantes F (2014) How I treat myelofibrosis. Blood 124(17): 2635-2642. https://doi.org/10.1182/blood-2014-07-575373

15. Pidala J, Craig BM, Lee SJ, Majhail N, Quinn G, Anasetti C (2013) Practice variation in physician referral for allogeneic hematopoietic cell transplantation. Bone Marrow Transplant 48(1):63-67. https:// doi.org/10.1038/bmt.2012.95

16. Tiribelli M, Palandri F, Sant'Antonio E, Breccia M, Bonifacio M (2019) The role of allogeneic stem-cell transplant in myelofibrosis in the era of JAK inhibitors: a case-based review. Bone Marrow Transplant doi 55:708-716. https://doi.org/10.1038/s41409-0190683-1

Publisher's note Springer Nature remains neutral with regard to jurisdictional claims in published maps and institutional affiliations. 